\title{
THE TERMINATOR
}

\author{
Dreams of another world.
}

\section{BY LAURENCE SUHNER}

$\mathrm{S}$ o. Here I am. At the line between dark and light. At the very border that separates the side facing the star from the one that remains eternally shaded. It's like being at the edge of the visible world, at the end of the observable Universe, in that grey zone, permanent twilight, where the shadows stretch, revealing the whimsical landscape. Yin and yang.

The noise of the engine fades. I need silence.

I step out on the foredeck of my ship-bathyscaphe, precious package in my hands. The swell rocks me, the wind whips me with such force that I have to grab the ship's rail. Ahead of me, at the bow, stretches the dark side. Like all the planets in this system, TRAPPIST-1e, renamed Nuwa by the first colonists, is in synchronous rotation. The same side always facing its sun, it provides a contrasted reality. Eternal night. Or eternal day. It all depends on where you are. East or west of the terminator.

Behind me, on the contrary, the surface of the deep ocean that covers a large part of this world glistens in the star's dark red glow. By balancing the large differences between the temperatures of the two hemispheres, it allowed life to bloom in conditions that initially seemed hostile. After lengthy observation surveys, biological markers were detected in the planet's atmosphere - water, carbon dioxide, oxygen, ozone, methane and the TRAPPIST-1 system was selected as one of the destinations for humanity's long extrasolar exile.

I stand on the deck a moment, fascinated by the ocean that darkens before me as it disappears into the night. Myriad stars riddle the waves: bioluminescence. Nuwa's ocean abounds with life forms that constantly move between the two hemispheres, following the currents and the movement of the violent winds generated by the contrast in the temperatures near the surface. These winds, along with the moderating power of the ocean, guarantee the existence of habitable regions on either side of the terminator, cooling the exposed side of Nuwa and heating the dark one.

I shiver at the thought of all those foreign creatures hiding in the depths under my ship's hull. The place where I've stopped is ideal for my task: there is a front and a back, a before and an after. The beginning or, depending, the end of the day. And the end of a life: my mother's.
After glancing at my instruments, I move the mask of my respirator aside. Here, there's no risk. Marine fragrances float in the air. It's $15^{\circ} \mathrm{C}$. Humans perceive the infrared radiation of the TRAPPIST- 1 star, an ultracool dwarf studied almost 400 years ago by astronomers on Earth, more as heat than visible light. But I would only have to venture a few dozen kilometres into the nightside for the temperature to drop and living conditions to deteriorate. In fact, it should be much colder because the planet receives less light than Earth. But the last three planets in the system have dense atmospheres that, combined with the ocean's action, attenuate the temperature variations while protecting us from the star's X-rays and ultraviolet radiation.

I feel the urn in my hands. So very light. I open the lid and a few particles escape, carried off by the wind.

All that is left of my mother. She arrived here, with me, at the end of a journey that took almost three centuries. She was 35 years old. I was five. I remember only the final weeks of the trip when, one by one, the occupants of the colonization ship came out of stasis to admire the first of the many planets in this small-scale system: a tiny star, barely larger than Jupiter, and its cortege of synchronous, telluric planets, including three with regions suitable for human settlement.

My mother's ashes scatter through Nuwa's thick air. They float up in the atmosphere, carried by an ascending current. They will eventually fall back into the sea, the sea I've spent my life skimming on my ship.

Waiting for the day when...

I look up and see TRAPPIST-1f, renamed Pangu, another planet in the system, so close that it would look like a half-moon in the skies of our cradle, Earth. Occasionally, from the island where I settled 20 years ago, I enjoy observing it through my telescope. On the dayside, I can make out the cities: Mélania, Béhor, Altaïra. The TRAPPIST-1 system, with its short interplanetary distances, makes space opera possible. Travelling from Nuwa to Pangu takes a week. A lilliputian system where worlds are like neighbouring countries.

Behind TRAPPIST-1f, farther still, TRAPPIST-1g, now called Shennong, floats. Its atmosphere, as dense as that of Venus, but less toxic, hides the surface of the planet. But, on very rare occasions, the gales that race over the globe grow so violent that they rip through the cloudy cover for a few seconds, unveiling a gigantic structure. The artefact. An aerial construction several kilometres tall. Perhaps a space elevator or an atmospheric processor?

I saw it once, the year I turned 20.

That event marked my life.

Since then, I've been waiting.

I'm waiting for the hypothetical day when we will be allowed to set foot on Shennong. For now, that world is off limits. All efforts to land have been aborted. No transmissions filter through the thick atmosphere.

But they're there.

And they're old. Their civilization emerged well before ours. They knew we were coming. They must have observed us in our interstellar tin can, as it gobbled up the 40 light years separating us from Earth.

But we discovered their existence only the day one of our exploration vessels attempted to get a little too close to Shennong.

I arm myself with patience. And I dream. Intensely. Like when I was a little girl.

One day.

One day, we may be allowed to visit that mysterious world.

When?

When we're wise, my mother said, a few months before her death.

I only hope that day comes during my lifetime.

Laurence Suhner is a Swiss science-fiction novelist and author of the QuanTika trilogy. She currently teaches creative writing at the University of Geneva. This story was translated from French by Sheryl Curtis. 